\title{
IDENTIDADES CRUZADAS: HISTÓRIA DO CERCO DE LISBOA E GESCHICHTE DER BELAGERUNG VON LISSABON
}

\author{
Orlando Grossegesse* \\ Universidade do Minho
}

\begin{abstract}
Resumo: É sabido que o romance História do Cerco de Lisboa empreende uma revisão da origem da identidade portuguesa revelando a sua frágil base histórica, no sentido de hibridismo cultural. Este estudo mostra como a narração da procura problemática da origem histórica está cruzada com a procura da origem do texto. Ao analisar a densa rede intertextual, na qual se emaranha a revisão criativa de Raimundo Silva, fica patente que a questão central desta metaficção historiográfica é menos a revisão do que a tradução. Nesta base, a aventura da leitura / escrita torna-se uma questão de identidades cruzadas que se prolonga no leitor do romance: no caso da tradução para alemão, tem de lidar com a afinidade cultural do leitor com os Cruzados.
\end{abstract}

Palavras-chave: Metaficção tradutológica. Hibridismo cultural em tradução.

* Possui M.A. em Filologias Românicas e Ciências da Comunicação pela Ludwig-Maximilians-Universität (LMU) de Munique, Alemanha, e doutorou-se nestas áreas pela mesma universidade, em 1989. Desde 1990 é docente (atualmente, professor associado) do Departamento de Estudos Germanísticos e Eslavos, Instituto de Letras e Ciências Humanas da Universidade do Minho, Braga, Portugal. E-mail: ogro@ilch.uminho.pt 


\title{
INTERSECTED IDENTITIES: HISTÓRIA DO CERCO DE LISBOA AND GESCHICHTE DER BELAGERUNG VON LISSABON
}

\begin{abstract}
It is well known that the novel The History of the Siege of Lisbon undertakes a revision of the origin of Portuguese identity by revealing the fragile historical fundament in the sense of a culture's hybridity. This study argues that in this story the problematic search for 'pure' historical origin is intertwined with the search for 'pure' text. By analyzing the dense intertextual net of Raimundo Silva's doubtful and creative proof-reading it becomes evident that it is less a question of proof-reading than of translating that is at stake in this historiographic metafiction. From this perspective the adventure of reading/writing turns out to be a question of criss-crossed identity that is extended to the novel's reader: in the case of its translation into German, the new text has to tackle with the reader's cultural affinity with the Crusaders.
\end{abstract}

Keywords: Metafiction about translation. Cultural hybridity in translation.

"É humilhante para os portugueses a percepção que o exterior tem de Portugal, (...)". Esta e outras afirmações, recentemente proferidas pelo gestor norte-americano Jack Welsh num congresso em Lisboa ${ }^{1}$, mereceram, para além de reações imediatas de indignação, um artigo de opinião de José Pacheco Pereira:

Welsh fez bem em dizê-lo e fazia-nos bem ouvir mais verdades como esta para substituirmos a nossa balofa e incompetente auto-estima pela percepção de que a realidade não é propriamente um espelho do nosso excesso identitário. (Pereira, 2006).

Pacheco Pereira reconhece que esta percepção não é acolhida de bom grado e logo classificada de "arrogância do estrangeiro". Em vez de assim "esconjurar o que não queremos ver", ele destaca a utilidade particular de sermos confrontados com a nossa imagem vista de fora, quando nos entregamos à "tarefa permanente de nos 
iludirmos" (Pereira, 2006). Nesta contraposição, predominam categorias rígidas e relações claramente antagónicas: realidade e ilusão; visão de fora e de dentro; capacidade de percepção e respectiva incapacidade. Contudo, a conclusão de os portugueses ficarem "mal amados, mal lembrados, pouco estimados no mundo", e o senhor Welsh ter lembrado isto "com crueldade", não vai muito além do citado "negativismo dos intelectuais, traço típico desde os Vencidos da Vida", que também não satisfaz o próprio comentarista, apesar de preferir "uma boa dose de realidade, cruel que seja" (Pereira, 2006). De facto, Pacheco Pereira opera com uma categoria de realidade difusa porque não expressamente identificada como construção política, social e cultural responsável pela afirmação das imagens, seja de fora ou de dentro. Portanto, a habilidade portuguesa de apropriar-se, ou até de antecipar a imagem de fora ${ }^{2}$, não questiona mas protege o excesso identitário. Esta construção da 'realidade portuguesa' entre duas atitudes antagónicas mas, em termos discursivos, no seu excesso análogas revela o desajuste da dicotomia entre a realidade cruel (de fora) e a doce ilusão (de dentro).

Em resumo, apesar da sua posição auto-reflexiva, o ensaio de Pacheco Pereira não transcende uma tradição discursiva bem definida: a de absorver posições negativas 'de fora' para preservar alguma identidade de Portugal entre a dramatização actual da sua perda total e a memória indelével da sua grandeza. Com este tipo de análise, afastamo-nos de posições substanciais de identidade: em vez de características próprias e inconfundíveis, bem demarcada face a outras identidades, através de território, sangue (povo) e língua, ela é entendida na sua dimensão estrutural de relacionamento ou discurso, seguindo o conceito de Wolfgang Welsch (1995) de transculturalidade como princípio fundamental da praxis da vida. ${ }^{3}$ Neste sentido, a fala sobre o próprio que se baseia nas 'verdades cruéis' ditas (ou dizíveis) pelo outro revela-se uma forma portuguesa de transposição dramática ou cómica que afirma as relações desenhadas nas dicotomias inicialmente referidas.

Ao contrário da representação de pureza cultural, a transculturalidade baseia-se na consciência de que somos, em termos de 
identidade cultural, essencialmente "mestiços" (Welsch, 43). Falamos de representação da identidade cultural (nacional) para realçar a sua construção discursiva ao longo da história: no Renascimento e no Barroco, portanto no alvor das nações europeias modernas, inauguraram-se modos de falar sobre o carácter da nação ou do povo, em termos comparativos. No Romantismo, estes discursos adquiriram maior força através da definição do carácter do povo (Volkscharakter) como essência pré-consciente, sucessivamente reinterpretada e amalgamada com o conceito pseudo-científico da raça, a partir do fim do séc. XIX. Esta evolução demonstra que não existe um objectivismo desvinculado da evolução da historiografia e etnografia. Tal como não existe uma substância intemporal da obra de arte, não pode haver uma substância intemporal do discurso historiográfico e etnográfico ou do discurso da identidade cultural (nacional). Conforme a crítica do platonismo subjacente nas filologias e na historiografia tradicionais, o analista de um texto não possui a priori uma posição superior ao 'leitor normal', mas deve ancorar a sua própria análise "na consciência de a sua posição actual se integrar numa sequência histórica de leitores"4. A partir destas definições da cultura e do texto analisaremos os cruzamentos de identidades no romance História do Cerco de Lisboa (1989) e na tradução alemã Geschichte der Belagerung von Lissabon (1992). ${ }^{5}$

O romance saramaguiano subverte, através de uma representação transcultural ou híbrida ${ }^{6}$, a coesão da identidade portuguesa perante o outro, de definição dupla: por um lado, os cruzados, na maioria procedentes do Norte da Europa, e, por outro, os mouros, oriundos de um Sul longínquo, não concretizado, e senhores atuais do território. São representações estereotipadas e, portanto, ambivalentes, tornando o outro ao mesmo tempo estranho e familiar: "the ambivalence of colonial cultural texts" dá origem à "production of hybridization" (Bhabha, 1985, 112-19), afirmando que "national narrative is the site of an ambivalent identification" (1994, 167). Precisamente a Tomada de Lisboa, que na historiografia nacional se constitui como episódio nuclear da génese da nação, é des-narrada (dénarrée; Prince, 1988) pelo revisor Rai- 
mundo Silva, o protagonista deste romance, partindo de um "não": "Os cruzados Não auxiliarão os portugueses a conquistar Lisboa" (Saramago, 50). A atitude de des-narrar que produz a indeterminação relativamente à versão supostamente verídica dos factos manifesta-se na problematização das fontes e no uso do futuro ao falar sobre os acontecimentos do ano de 1147, partindo desta negação explícita que o revisor introduz no livro de um historiador ${ }^{7}$, antes da sua publicação, sem possuir nenhuma autoridade para este acto (Grossegesse, 1996, 810). Portanto, não só o discurso, mas também a própria acção deste romance questionam os conceitos de identidade cultural original e texto original.

Assumindo, aos poucos, a tarefa de uma reescrita com base no "não", Raimundo procura uma "fonte limpa", lamentando a "imprecisão dos dados" e a "propagação alucinada das notícias", dando-se a "proliferação das próprias fontes segundas e terceiras" que ele compara com a "multiplicação de esporos" (124) e - numa analogia com a actualidade - com a "repetição variada, nas notícias dos jornais" (Saramago, 125). A procura da origem da nacionalidade entretece-se com a procura do texto da origem, revelando-se cada vez mais a impossibilidade de encontrar pureza identitária: nem existe uma identidade-fonte, nem um texto-fonte, porque ambas as noções colocariam cultura e escrita fora de uma evolução ou discursividade histórica. Ora, se a "verdade" da origem e o seu discurso unívoco ficam desconstruídos, posição já anunciada pela epígrafe, tirada de um Livro dos Conselhos imaginário ${ }^{8}$, como pode haver então uma tradução deste romance no entendimento tradicional que se baseia na 'verdade' de um texto-fonte e procura a consistência comparável de um texto-alvo?

É precisamente a alternativa imaginada de uma conquista de Lisboa sem recorrer ao auxílio de estrangeiros que expõe a vulnerabilidade do 'excesso identitário' implícita na História nacional quando se fala da "ajuda de cruzados, dando à participação deles um valor instrumental quando seria mais correcto dizer que Lisboa foi conquistada com a ajuda dos portugueses" (Caragea, 224). $\mathrm{Na}$ procura de minimizar o papel da participação estrangeira, já 
bem visível na Crónica de D. Afonso Henriques (1632), de Frei António Brandão, através de uma compilação comentada de fontes, chegou-se, de facto, no Estado Novo, até à sua negação, num texto de José Augusto de Oliveira (1940). No entanto, esta revisão nacionalista não conseguiu alterar a presença já sedimentada dos cruzados no imaginário português: etnicamente heterogéneos, no entanto unidos aos portugueses por serem também eles cristãos e hostis aos muçulmanos. Neste sentido, a representação do encontro com os cruzados é significativa. Na Crónica de Portugal de 1419, citada no romance sob o título anterior Crónica dos Cinco Reis de Portugal", no capítulo "Como el·rey dom Afonso se ordenou de ir çerquar Lixboa e das jentes estrangeyras que levou em sua ajuda", encontramos a seguinte descrição:

(...) moverom em aquele tempo muytas jentes de Ingraterra e d·Alemanha e de Framça e vierom em muyto grande frota pelo mar, em guisa que achamos espírito que erom oytenta velas. E, vindo todolas naos de mar em fora busquar terra à roqua de Syntra, el·rey, que estava em çima no castelo com seus fidalguos, devisaram-nos e, quando virom tão grande frota como aquela, foram muy espantados. E el'rey mandou loguo quatro cavaleyros que fossem à ribeyra saber que gemtes erom aquelas. (...). E os cavaleyros perguntaram que gemtes erom e os das naos lhe disserom que erom christãos que partirom de suas terras e vinhom às Espanhas para guerear contra os mouros por fazer serviço a Deos. (Crónica, 47)

A chegada dos estrangeiros, cuja força militar espanta, insinua uma espécie de invasão amigável nas "Espanhas", logo funcionalizada pela História nacional como dádiva divina para a génese da identidade portuguesa, de grande coesão, força e predestinação, já afirmadas pelo milagre de Ourique. Através da reinvenção dos actores históricos e dos seus discursos, o romance saramaguiano nega, de uma forma paródica, o conceito de identidade cultural 
que se define, na tradição herderiana, através do antagonismo entre cultura própria e alheia. Como mostra a Crónica de 1419, a identidade alemã também participa no Cerco de Lisboa, integrando-se na categoria heterogénea dos estrangeiros do lado colonizador, superiores não só relativamente aos mouros mas também aos colonizadores autóctones que, ao consentir ou adoptar a ideologia importada da cruzada, se revelam, em certa medida, também colonizados. Na noção da milagrosa invasão amigável de estrangeiros que vinham aqui "para guerear contra os mouros" dá-se azo ao excesso identitário que se sobrepõe à contra-imagem humilhante de um papel meramente secundário de anfitrião e ajudante numa conquista de Lisboa liderada pelos cruzados, por sua vez missão menor e de passagem no seio de um contexto maior, o da Segunda Cruzada (1147-49). ${ }^{10}$

Um romance que não só reescreve, de uma forma paródica, a origem da configuração colonizadora / colonizada específica, responsável do excesso identitário português, mas também sugere 'leituras' anacrónicas da actualidade portuguesa, ainda caracterizada pelo dilema deste mesmo excesso identitário, como comprova o ensaio de Pacheco Pereira (2006), é difícil de traduzir porque implica uma operação complexa de mediação cultural no sentido de "cross-linguistic cultural practice involving recontextualization” (House, 2002 , 97). Ilustramos esta dificuldade com um episódio do livro do historiador, lido por Raimundo Silva, antes de introduzir o "não":

(...) agora o historiador embandeirou o estilo para tratar da grande discórdia que se levantou entre os cruzados, (...), sobre se deveriam, ou não, ajudar os nossos portugueses a tomar Lisboa, se ficariam aqui ou seguiram, como previsto, para a Terra Santa, onde os estava esperando Nosso Senhor Jesus Cristo, sob os ferros turcos. Argumentavam aqueles a quem seduzia a ideia de ficar que lançar fora da cidade a estes mouros e fazê-la cristã seria também serviço de Deus, contestavam os contrários que, se esse era serviço de Deus, serviço menor seria, e que cavaleiros tão principais como 
ali todos se prezavam de ser tinham por obrigação acudir aonde mais trabalhosa fosse a obra, não neste cu do mundo, entre labregos e tinhosos, que uns deviam ser os mouros e outros os portugueses, porém não o averiguou o historiador, talvez por não valer a pena de escolher entre os dois insultos. (Saramago, 47)

(...) nun übt sich der Historiker in hohem Stil, um den groBen Zwist darzulegen, der sich unter den Kreuzfahrern (...) entspann, stand doch die Frage, ob sie unseren Portugiesen bei der Einnahme Lissabons helfen sollten oder nicht, ob hier verbleiben oder aber, wie vorgesehen, weiterziehen, ins Heilige Land, wo in türkischen Fesseln Unser Herr Jesus Christus ihrer harrte. Es argumentierten jene, die am liebsten hiergeblieben wären, die Mauren aus dieser Stadt treiben und aus ihr einen Christenhort zu machen sei gleichermaßen ein gottdienliches Werk, und die anderen hielten dagegen, wenn gottdienliches Werk, dann doch wohl ein minderes, so hehre Ritter, wie alle hier es zu sein vermeinten, hätten die Pflicht, dorthin zu eilen, wo das Werk mühevoller sei, nicht wie in diesem Weltenwinkel unter Bauersleuten und Wichten, gemeint waren wohl mit den einen die Mauren und mit den anderen die Portugiesen, doch unterließ der Historiker weitere Ergründung, vielleicht weil beides Schmähworte waren. (55)

Seja por entender "embandeirar o estilo" num sentido estrito, em vez de intuir a subversão da escrita pelas vozes citadas, no sentido da polifonia bakhtiniana ${ }^{11}$, seja por obedecer a um conceito do politicamente correcto, a versão alemã "Weltenwinkel" evita o equivalente "Arsch der Welt" da expressão escatológica "cu do mundo", estereotipada no discurso da identidade portuguesa do século XX. Também suaviza os insultos que expressam a superioridade colonizadora dos cruzados não só relativamente aos mouros mas também aos portugueses: a tradução inofensiva de "Bauersleute" e "Wichte" anula a semântica insultuosa de "labregos" 12 e 
"tinhosos". Com isto, atenua-se a atitude de arrogância dos "cavaleiros tão principais", que não acham necessidade de diferenciar entre portugueses e mouros. A tradução não consegue transferir a paródia da identidade portuguesa, que dialoga com o leitor implícito (Iser, 1972) do original, para o perfil do leitor da tradução, de maior afinidade cultural com os cruzados. Trata-se de um leitor desprovido (1) da "enciclopédia do mundo português" (Caragea, 209) e (2) da socialização no contexto da realidade política e social portuguesa dos anos oitenta e noventa, com a memória do 25 de Abril de 1974 (por exemplo, implícita no perfil da personagem Mogueime como pré-figuração de Salgado Maia).

Esta dupla dificuldade, que - com o tempo - também surgirá cada vez mais para o texto-fonte, conduz à questão do texto comentado que discute Horst Turk (1992), exemplificando-a no romance La reivindicación del conde don Julián de Juan Goytisolo (em reedição comentada, a partir de 1985) e na sua tradução alemã (não comentada). No caso de História do Cerco de Lisboa, ainda não existe uma edição comentada do original. Entre as traduções, a alemã de Andreas Klotsch (1992) prescinde de comentário, tal como a inglesa de Giovanni Pontiero (1996) que se cinge a um breve prefácio; no entanto, a romena, por exemplo, é acompanhada por um prólogo extenso e notas explicativas da tradutora Mioara Caragea. ${ }^{13}$ Pelo comentário e pela ausência dele acentuam-se as duas caras de Iano (Janusköpfigkeit) da tradução: ela representa o texto-fonte e substitui o texto-fonte na literatura-alvo. Mais ainda, a tradução é também em todas as literaturas um lugar privilegiado para articular qualidades de diferença. ${ }^{14}$ Destas deliberações surge como questão central: a tradução alemã não comentada da História do Cerco de Lisboa é capaz de transmitir a paródia de identidade / alteridade cultural (nacional) do texto-fonte?

Ao falar do handicap do leitor desprovido da "enciclopédia do mundo português" (Caragea, 209), prolonga-se a abordagem purista em vez de se repensar também esta enciclopédia de forma transcultural. Com isto, evidencia-se o cruzamento de identidades, em constante mudança desde as fontes históricas citadas no 'livro 
do historiador' até à própria tradução do romance. Já o historiador cujo livro Raimundo Silva revisa concede destaque entre as fontes ao "célebre Osberno" (Saramago, 124), privilegiando assim a narrativa epistolar de um cruzado, oriundo da região de Norfolk ou Suffolk, que participou no Cerco. Atualmente, é considerada "talvez a principal fonte histórica" (Alves, 13). A carta, dirigida a uma personalidade inglesa, está escrita em latim. Por isso, Crucesignati anglici epistola de expugnatione olisiponis ${ }^{15}$ integra não só uma visão desde o exterior, portanto afastada da construção da História nacional, mas também um texto noutra língua. A própria narrativa marginaliza a identidade portuguesa: não só no contexto geral do antagonismo entre cruzados (identidade comum: francos) e mouros ${ }^{16}$, mas também pela divisão entre, por um lado, normandos e ingleses (no texto, a identidade própria) e, por outro, colonenses e flamengos, não só desunidos na decisão inicial (participar ou não) mas também com diferentes comportamentos durante o cerco e no saque da cidade conquistada (Conquista, 83). Com estas características, este texto fornece, por um lado, bases para uma narração fundadora da identidade portuguesa, desvalorizando sobretudo eticamente a colaboração dos cruzados, e, por outro, o pré-texto de uma des-narração transcultural, aproximando-se da historiografia crítica mais recente, na qual se procede a uma negação da narrativa fundacional nacional. ${ }^{17}$ As possíveis releituras fundamentam a paródia do ,excesso identitário' português no romance saramaguiano que se centra na retroprojeção anacrónica, não só da categoria de nacional, mas também da outra, da categoria de estrangeiro. Basta pensarmos no anacronismo das quinas de Portugal (só a partir de Sancho I) a substituir o crescente (na realidade, invenção do império otomano), que despertam a ira do revisor quando chega às páginas finais do 'livro do historiador' (41-42). Nada disto se encontra nas fontes. Também a tradução "passou a corrupta mesquita a puríssima igreja católica" (40) enfatiza um antagonismo identitário (muçulmano / cristão) que no texto-fonte fica subentendido: "purificatum est templum" / "foi purificado o templo" (Conquista, 85). Mais interessante relativa- 
mente ao leitor implícito de traduções para as línguas do Centro / Norte da Europa é o seguinte trecho:

O pessoal que veio a esta fala parlamentar é todo de portugueses, não pareceu bem a el-rei servir-se de estrangeiros para o reforço do ultimatum, ainda que, diga-se de passagem, subsistam grandes dúvidas de que o arcebispo de Braga pertença, de facto, ao nosso sangue lusitano, mas enfim, já nesses antigos tempos tinha principiado a fama que mantivemos até hoje de receber bem a gente de fora, distribuir-lhes cargos e prebendas, e este D. João Peculiar, vá lá, pagou-nos multiplicado em serviços patrióticos. E se, como também se diz, era mesmo português, e de Coimbra, vejamo-lo como pioneiro da nossa vocação migratória, da magnífica diáspora, pois toda a sua juventude a passou em França, a estudar, devendo notar-se aqui uma acentuada diferença em relação às tendências recentes da nossa emigração para aquele país, plutôt adstrita aos trabalhos sujos e pesados. (197-98)

O problema de transmitir o sentido paródico na tradução ${ }^{18}$, por exemplo da eterna vocação migratória, „unserer migratorischen Berufung, unserer wundervollen Diaspora“ (240), culmina na dificuldade de incluir o leitor implícito da tradução na situação enunciativa, isto é: neste caso, ele se deveria rever no 'estrangeiro' vindo da França e, indo além das dicotomias, aperceber-se da relatividade das categorias.

É significativo que o revisor Raimundo Silva chegue a este tipo de des-narração através de uma crítica da tradução que fundamenta o próprio acto de alterar o 'livro do historiador' a partir do "não". Não é tanto o "rigor da tradução" (44) que está em causa, mas a sua verossimilhança. Precisamente por duvidar dos conhecimentos de latim, das capacidades retóricas e, em geral, da cultura de Afonso Henriques, Raimundo Silva considera "a primeira fala averiguada do nosso rei fundador" nada menos do que "uma absurdidade" 
(43), negando, de passagem, também o uso da língua portuguesa que a tradicional narrativa fundacional de Portugal assume com naturalidade:

(...) é de supor que o real menino, além de explicar-se naturalmente em galego, latinizaria o quantum satis para poder declamar, chegada a hora, perante tantos e tão cultos cruzados estrangeiros, a arenga supracitada, uma vez que eles, de línguas, não entenderiam então mais do que a sua de berço e iguais rudimentos da outra, com a ajuda dos frades intérpretes. (Saramago, 44)

Esta dúvida sobre a pureza do discurso régio, reproduzido na epístola e traduzido pelo historiador, torna-se em "leitura paródica (...) pela contextualização dramática” (Caragea, 2003, 235). O que Raimundo Silva "em voz alta lê, como um arauto lançando as proclamas" (P 45), "situando portanto a sua reinterpretação na zona pragmática da pronuntiatio" (Caragea, 235), corresponde ipsis verbis, com uma ou outra inversão, à tradução de J.A. de Oliveira (Conquista, 44). A performance retórica não só “acaba de inculcar no revisor um sentimento de distanciamento irónico em relação às palavras do rei" (Caragea, 235) mas questiona sobretudo as noções de texto-fonte e tradução fiel ao texto-fonte.

Ao aprender que a invisibilidade do tradutor é falaz, o revisor dá o primeiro passo para a sua própria visibilidade autoral. Assim, a "metaficção historiográfica" (Kaufman, 1991) nasce directamente do dialogismo, no sentido bakhtiniano, com José Augusto de Oliveira: simultaneamente, ele é tradutor da epístola, publicada em edição bilingue (1935), e autor da revisão historiográfica intitulada "D. Afonso Henriques empreendeu a conquista de Lisboa sem contar com o auxílio dos cruzados", apresentada em 1940. Em vez de tomar a epístola "dita de Osberno" como texto-fonte homogéneo e traduzi-lo do latim, como o fez o "próprio autor da História" (Saramago, 43), facilmente reconhecível como figuração de José 
Augusto de Oliveira, Raimundo Silva duvida não só da pureza da fonte e, subsequentemente, da fidelidade da tradução, mas também da identidade do autor da epístola. Pelo título Conquista de Lisboa aos Mouros (1147) Narrada pelo Cruzado Osberno, testemunha presencial da edição bilingue, esta identidade parece unívoca, mas não é: por exemplo, José F. Alves (2004) considera "bem coerente" que a primeira linha do texto latino, "Osb. de Baldr. R. salutem", indique um Osb. de Baldr. (Osberno, ou Osberto, ou Osborne) como destinatário de "uma missiva mesmo sobrescrita apenas por um R.", conjecturando-se o nome de Rogério. ${ }^{19}$ Aportuguesando-se o nome Roger para Rogeiro, o romance História do Cerco de Lisboa assume esta suposição - em oposição ao 'livro do historiador' que considera Osberno um cruzado letrado. O frade é apresentado na frase que continua a citação anterior sobre a identidade étnica indefinida de D. João Peculiar, arcebispo de Braga:

Quem é indubitavelmente estrangeiro, mas contado à parte por vir em missão especial, nem parlamentário nem homem de guerra, é aquele frade ruivo e sardento, ali, a quem agora mesmo ouvimos chamar Rogeiro, mas que realmente tem por nome Roger, o que deixaria em aberto a questão de ser ele inglês ou normando, (...). (198)

A identidade de Roger / Rogeiro, embora etnicamente indecisa, oferece - na tradução para inglês e também para alemão - uma afinidade cultural com o leitor implícito, reforçada pelo físico inconfundível nórdico: "that sandy-haired, freckled friar" (Saramago, 1996, 176); „jener blonde sommersprossige Pater“ (241). No romance, Frei Rogeiro cumpre o papel de "cronista" que transpõe um conjunto multilingue de falas numa escrita coerente e homogénea. Por exemplo, no caso do discurso do arcebispo de Braga:

Rogeiro logo em abreviado e taquigráfico o registou, para mais tarde deixando os aformoseamentos oratórios com que 
brindará aquele seu destinatário distante, Osberno chamado, lá onde quer que esteja e quem quer que tenha sido, porém já vai introduzindo redondeios de lavra própria, frutos de inspiração estimulada, (...) (200).

Significativamente, Roger / Rogeiro não é tradutor mas - tal como o revisor Raimundo Silva - portador da consciência de que tudo é tradução, correspondendo ao latim o privilégio da língua veicular:

Este Rogeiro não conhece uma palavra de arábigo nem de galego, mas neste caso não será impedimento a ignorância, pois todo o debate, vá por onde vá, sempre irá dar ao latim, graças aos intérpretes e aos tradutores simultâneos. (198)

De facto, esta consciência do plurilinguismo caracteriza Crucesignati anglici epistola de expugnatione olisiponis desde o início, falando dos cruzados: "Inter hos tot linguarum populos firmissima concordiae atque amititiae" (Conquista, 21). As falas de cruzados, portugueses e mouros aparecem ou em citações traduzidas (de outras línguas para latim) ou em língua latina para serem traduzidas, no contexto do cerco. Ambas são adaptadas a um texto composto conforme as retóricas clássica e bíblica. É a própria epístola que refere a necessidade de tradução, por exemplo do discurso do bispo do Porto, proferido em latim perante a multidão plurilingue dos cruzados reunidos. ${ }^{20} \mathrm{Em}$ contraste, é significativo que o tradutor J.A. de Oliveira defenda "uma versão que, sem trair o pensamento, se libertasse da escravidão da letra" em vez de encher "o texto português com antigos vocábulos, forrageando-os nas velhas crónicas conhecidas dos eruditos" (Oliveira, 1935, 18), outorgando à sua tradução uma missão nacionalista:

Assim, espero-o, todos entenderão este velho monumento da nossa história e, nesta hora de ressurgimento, neste des- 
pertar de energias e rasgar-se de horizontes novos, fará bem aos portugueses de hoje ouvir falar a alma dos que à força de braço, com persistência, com teimosia, com obstinação e com amor, souberam ungir com o próprio sangue os alicerces desta nossa Pátria que eles nos deixaram, para a conservarmos amorosamente digna, honrada e livre. (Oliveira, $1935,19)$

Quem afirma assim uma leitura nacionalista de uma epístola no fundo totalmente alheia ao objectivo de alicerçar a História nacional, esconjura o que não quer ver, entregando-se à "tarefa permanente de nos iludirmos" que critica Pacheco Pereira (2006) no caso das reacções ao discurso de Jack Welsh. Longe de compreender a utilidade particular do confronto com a nossa imagem vista de fora, J.A. de Oliveira concebe a sua tradução da epístola estrangeira como contributo à legibilidade culturalmente coerente e homogénea do "velho monumento da nossa história". A fidelidade da tradução revela-se enganadora através da leitura crítica de Raimundo Silva. Assim, a palavra árabe "algazarra" que J.A. de Oliveira escolheu para traduzir "conclamatio" na fala (por sua vez traduzida) de D. Afonso Henriques ${ }^{21}$, evidencia não só a homogeneização do plurilinguismo, tanto no texto-fonte como na tradução, mas também - numa leitura contrária - a crioulização da identidade portuguesa:

Acertara D. Afonso Henriques em cheio quando prognosticou que o exame da sua proposta acabaria em algazarra, palavra que sendo árabe de nacionalidade igualmente serve a qualquer gritar e vozear de colonenses, flamengos, bolonheses, bretões, escoceses e normandos, misturados. (47-48)

Vollkommen recht hatte Dom Afonso Henriques mit der Voraussicht, sein Vorschlag werde eine algazarra auslösen, dieses Wort, obzwar arabischer Abkunft, ist auch dienlich jedwedes ereiferndes Geschrei und Gekreisch der Kölner, 
Flamen, Bologneser, Bretonen, Schotten und Normannen, und aller durcheinander, zu bezeichnen. (56)

Portanto, a palavra "algazarra" sugere, nesta leitura transcultural do discurso régio, a relação ambivalente galega / árabe como fundadora. Esta insinuação integra-se numa paródia do discurso da identidade nacional, nomeadamente na sua projecção anacrónica para a Idade Média - um aspecto que fica esbatido na tradução alemã. ${ }^{22}$ Uma leitura semelhante sugere a mensagem do rei de Évora aos "seus irmãos de Lisboa", cuja tradução comentada ao português actual brinca com a identidade estereotipada de alentejanos:

Aguentem aí os malvados, que a minha tropa de alentejanos já vai a caminho, dizemo-lo assim por vir essa gente de além do Tejo, ficando demonstrado, de caminho, que já havia alentejanos antes de haver portugueses. (176)

Para o leitor da tradução, a existência historicamente invertida de "Alentejaner" antes dos "Portugiesen" não possui significado, centrando-se a atenção na identificação de "diese Leute von jenseits des Tejo" como "Alentejaner" (212). De facto, a epístola latina cita mensagens entre os mouros de Lisboa e o rei de Évora, destacando a ajuda de um intérprete para poder incorporá-las no texto. ${ }^{23}$ Obviamente, a missiva régia não menciona alentejanos e transmite precisamente o contrário: a recusa do envio de tropas, alegando a existência de "tréguas com o rei dos portugueses" (Conquista, 64).

Estas manipulações mostram que Raimundo Silva é cada vez mais consciente da leitura / escrita como cruzamento entre dimensão linguística e cultural no eixo temporal, válido para a questão da tradução ${ }^{24}$, no sentido das reflexões de André Lefevere (1992), Horst Turk (1992) e Susan Bassnett (1998) que analisam o texto traduzido "embedded in its network of both source and target cultural signs" (Bassnett,9). Transcendo uma definição estática de "cultural signs" e da "hybridization" de Homi Bhabha, podemos falar da 
tradução como crioulização (Stoll, 2005), com base em múltiplos processos de mudança, sincrónicos e diacrónicos. A paródia da génese da identidade portuguesa através da crítica da pureza do texto-fonte (e da sua tradução) coincide com posições da historiografia moderna: a conquista de Lisboa não significa - conforme a História nacional tradicional - a vitória dos portugueses alcançada com ajuda dos cruzados sobre os mouros; significa, isso sim, a imposição militarmente bem sucedida do novo paradigma de pureza cristã, implantada através da ideologia colonizadora da Segunda Cruzada (1147/48), ao velho paradigma da convivência segregada, mais ou menos pacífica entre muçulmanos, cristãos e judeus, em estruturas políticas e sociais localmente autónomas, sob domínio árabe (Marques, 68). O romance saramaguiano insinua esporadicamente a crioulização da identidade portuguesa mas não concede potencial identitário às populações cristã (moçárabe) e judaica de Al-Usbuna, sacrificadas por uma fracção dos cruzados "logo que o saque e o massacre exorbitaram das possibilidades de controlo" (Marques, 68), como conta em pormenor a epístola. Naturalmente, destaca-se o bom comportamento dos ingleses e normandos (identidade de quem escreve) em contraste com o massacre e a devastação perpetrados pelos colonenses e flamengos que até matam o bispo da cidade moura. ${ }^{25}$

Portanto, o des-narrar saramaguiano não empreende um deslocamento transcultural tão audaz como, por exemplo, La reivindicación del conde don Julián (1970) de Juan Goytisolo. ${ }^{26}$ Naquele romance, o narrador recupera, através da sua identificação com o mítico 'traidor' D. Julião, a identidade árabe e moçárabe, terminando com o anúncio, do lado árabe: "mañana será otro día, la invasión recomenzará”. No entanto, existe em História do Cerco um almuadem cego que preenche claramente o lugar do bispo antiquíssimo, a ser degolado como aquele, por "um soldado cristão, de mais zelosa fé" (348). A sua cegueira, paradoxalmente visionária da Lisboa moura sitiada, é contrária daquela de "ira sanguinária" do seu assassino, identificado como "o cruzado Osberno, só igual de nome" (Saramago, 40), introduzindo-se assim deliberadamente 
uma homonímia com o Osberno da epístola (ainda tratado - erroneamente - como o seu autor), novamente recordada em "o cruzado Osberno, porém não o tal". ${ }^{27}$

Esta duplicação de identidades com o mesmo nome adverte o leitor para ficar atento perante redefinições identitárias como, por exemplo, dos sitiadores chamados "os francos e os galegos" 28 sob comando dos cruzados e "Ibn Arrinque, o Galego" (74), na perspetiva dos mouros, recriada na mente de Raimundo Silva. O almuadem na sua torre complementa - através dos tempos a posição de Raimundo Silva, "que hoje quase tão cego se vê como ele" (33). Significativamente, o revisor apercebe-se "de que mora no preciso lugar onde antigamente se abria a Porta de Alfofa", configurando-se assim topograficamente a incerteza (que corresponde ao des-narrar), "se Raimundo Silva é um sitiado ou um sitiante, vencedor futuro ou perdedor sem remédio" (75). Nos seus passeios por Lisboa, ele revivifica uma cidade dividida entre zonas dos sitiados e dos atacantes, entretecendo "dois tempos" (242), passado e presente. ${ }^{29}$ A ambiguidade, nos eixos de lugar e tempo, transfere-se não só à história, aplicando o tema da cegueira até ao processo da sua recepção: “(...) esta [história] de agora, começada, só poderá lê-la quem os olhos tiver lúcidos e abertos, não um cego" (243); transfere-se também à língua, na qual está escrita o texto, insinuando-se um regresso a outra fonte, nas duas dimensões de identidade cultural e texto, que evoca aquela transformação da língua castelhana em árabe realizada nas últimas duas páginas de Juan sin Tierra (1975) de Juan Goytisolo: “(...), as mãos de Raimundo Silva pousam sobre a última folha escrita, umas linhas negras indecifráveis, talvez de arábiga língua, não estivemos atentos à voz do almuadem" (Saramago, 243). Na ação mediadora do revisor confluem a voz árabe do almuadem e a escrita latina do clérigo Roger. Na reescrita, inicialmente só mental, do 'livro do historiador', Raimundo Silva procura uma reconstrução contextualizada de ambos os lados (cristãos / muçulmanos), por exemplo corrigindo o significado da cegueira do almuadem: 
(...) não foi erro escrever, porque, enfim, escrito está, que era cego o almuadem. $\mathrm{O}$ historiador só fala de minarete e muezim, talvez ignorasse que quase todos os almuadens, naquele tempo e por muito tempo depois, eram cegos. (29

(...) es war kein Fehler, und geschrieben ist es nun mal, daß der Muezzin blind war. Der Historiker, der da lediglich von Minarett und Muezzin schreibt, wußte vielleicht nicht, daß fast alle Muezzins damals, und noch lange danach, blind waren. (32)

O revisor identifica "minarete" e "muezim" como palavras ligadas ao orientalismo dos séculos XVIII e XIX. Apesar de ser um fenómeno transnacional europeu, o orientalismo teve maior atracção na cultura francesa, que espalhou para outras línguas europeias as vozes árabes importadas pela via oriental: o Império Otomano (Turquia), na sua expansão europeia a partir do século XIV (ponto alto: conquista de Constantinopla, em 1453), tinha deixado vestígios, nomeadamente na cultura austríaca, no âmbito dos Türkenkriege (ponto de viragem: Cerco de Viena, em 1683) que serviram de base para o orientalismo francês. Raimundo Silva prefere o uso da palavra "almuadem", de maior e mais antiga presença na língua portuguesa ${ }^{30}$, importada directamente e recuperada no Romantismo pelas Lendas e Narrativas de Alexandre Herculano, tal como "almádena" em vez de "minarete" (Machado, 62). A tradução alemã não assinala esta tentativa de maior 'pureza' histórica no discurso sobre a identidade moura, mantendo a denominação invariável "Muezzin", embora exista a alternativa lexical menos usada de "Muaddhin" (Brockhaus, 229). ${ }^{31}$

No contexto do pensamento pós-colonial, esta reaquisição dos processos de imaginação depois das imposições coloniais europeias que começa, em princípio, pelo Romantismo (Herculano, Garrett), revela a raiz histórica da especificidade relacional portuguesa colonizada / colonizadora, isto é: a harmonização, mais ou menos voluntária, da política existente de poder regional na Península Ibé- 
rica com a ideologia colonizadora das cruzadas. Para além de uma subtil reivindicação da identidade moura, História do Cerco de Lisboa se cinge quase unicamente à revisão da identidade conquistadora, na qual entra a identidade alemã - um aspecto importante para a tradução. Assim, estabelece-se uma certa inversão, embora não perfeita, de identidade / alteridade: em geral, o leitor alemão está pouco familiarizado com a génese da identidade portuguesa e ignora a configuração colonizadora / colonizada específica que é responsável pelo excesso identitário, desconhecendo também a participação bem documentada de actores vindos de terras alemãs. Eles aparecem no romance, logo quando Raimundo Silva começa a reler a epístola, na sua procura da "fonte limpa":

\begin{abstract}
(...) a informação é de boa origem, diz-se que directamente do célebre Osberno, e assim podemos ficar a saber que estava o conde Arnoldo de Aarschot, o qual comandava os guerreiros vindos de diversas partes do império germânico, que estava Cristiano de Gistell, chefe dos flamengos e bolonheses, (...). (124)
\end{abstract}

Seguindo a teia intertextual, regressamos ao texto-fonte que, em contraste com a citada Crónica de Portugal de 1419, narra na perspectiva de uma expedição militar:

Igitur apud portum de Dertemunde diversarum nationum et morum et linguarum gentes navibus cicrciter CLXIIII convenere. Horum omnium trifariam partitur exercitus. Sub comite Arnoldo de Arescot nepote Godefridi ducis a romani imperii partibus secedit exercitus. Sub Christiano de Gistello flandrenses et bononenses. ${ }^{32}$

A mudança para "império germânico" (124) corresponde à nota explicativa do tradutor J.A. de Oliveira. ${ }^{33}$ No entanto, não se expli- 
ca a substituição de "bononenses" por "bolonheses". Naturalmente, as duas mudanças reflectem-se na tradução alemã que toma o romance saramaguiano como texto-fonte:

(...), Information aus verläßlicher Quelle, dem Vernehmen nach direkt vom berühmten Osberno persönlich, und also können wir uns vergewissern, daß da Graf Arnoldo de Aarschot zugegen war, der die aus verschiedenen Regionen des deutschen Kaiserreiches herbeigeströmten Krieger befehligte, und Cristiano de Gistell, der den Flamen und Bolognesern vorstand, (...). (150)

Na tradução alemã, nomes próprios estrangeiros não são 'repatriados', nem o próprio Osberne, nem Arnold ou Christian que ficam todos na grafia românica. No entanto, "império germânico" passa para "deutsches Kaiserreich", uma tradução que insinua uma projecção anacrónica do século XIX (refundação do Heiliges Römisches Reich Deutscher Nation como Deutsches Kaiserreich, em 1871), não pretendida no texto-fonte. Naturalmente, a tradução alemã ignora a possibilidade latente, já apagada no texto saramaguiano, de encontrar a identidade alemã nos "bononenses", mal transcritos em "bolonheses". ${ }^{34}$ Esta transcrição defeituosa surpreende, porque é a personalidade do cavaleiro Henrique de Bona, ausente na epístola ${ }^{35}$, que teve o maior relevo individual na historiografia portuguesa entre os "samtos cavaleyros martires":

Nesta tomada de Lisboa morerom alguns cavaleyros como martires e depois faziam muytos milagres, amtre os quaes foy hum cavaleyro chamado Amriqe, alemão, o qual era de hũa vila que chamom Bona, posta jumto de Colonha, o qual foy enterado em Sam Viçemte, honde fazia muytos milagres, (...). (Crónica, 50) 
Merecendo destaque na história da fundação do mosteiro de São Vicente, com episódios de acção milagrosa depois de morto (Indiculum, 83-85; Crónica, 50-52), Henrique de Bona torna-se uma personagem da História portuguesa digna de entrar n' $\mathrm{Os} \mathrm{Lu}$ síadas (VIII, 18). Procede-se a uma apropriação do estrangeiro colonizador: o alemão Henrique torna-se, depois de ter vertido "de gram voontade o seu sangue antre os mouros pola paixom do Nosso Salvador Jesu Cristo" (Indiculum, 83), no maior Santo Cavaleiro da Tomada de Lisboa. Na Alemanha, ele está totalmente desconhecido, a não ser no âmbito da retórica diplomática bilateral, na qual aparece, não como mártir mas como fundador dos "laços da amizade secular que liga o povo da Alemanha ao de Portugal" (Ehrhardt, 11), projectando a ajuda dos cruzados na génese do reino de Portugal numa 'lenda de auxílio' para todas as épocas posteriores.

Numa abordagem crítica, observamos um duplo branqueamento: (1) da memória do saque cruel e devastador da Lisboa moura, perpetrado pelos cruzados colonenses e flandrenses, e (2) da relação colonizadora entre aliados, no contexto da Europa. Cingimo-nos, no âmbito deste estudo, à análise do episódio da torre móvel. No romance, a ideia da sua construção é atribuída ao cavaleiro Henrique, manipulando as fontes históricas que falam de engenhos militares em competição, entre os diferentes grupos étnicos, ou destacam "um engenheiro italiano, natural de Pisa". ${ }^{36} \mathrm{O}$ discurso profético de superioridade cultural deste cavaleiro revela os motivos desta escolha:

Grandes são as vantagens que a Portugal advirão de imitar, neste como noutros casos, o que na Europa se vai fazendo de mais moderno, ainda que ao princípio experimenteis dificuldades em meter na cabeça as tecnologias novas, eu, por mim, sei da construção das tais torres o suficiente para os naturais daqui, (...). (251) 
Große Vorteile sind Portugal gewiß, wenn es, in diesem wie in anderen Fällen, nachahmt, was man in Europa an höchst modernen Dingen tut, mag es euch anfänglich auch schwerfallen, die neuen Techniken in euren Kopf hineinzukriegen, ich meinerseits weiß vom Bau besagter Türme hinreichend viel, um die hiesigen Eingeborenen zu unterrichten, (...). (305)

Mesmo a tradução alemã transmite a ideia de que a fala do cavaleiro Henrique perante o primeiro rei português contém uma paródia do discurso político actual que não se cansa de propagar a imitação da Europa avançada, representada pela capacidade económica e tecnológica de Alemanha em competição com outras nações. Ao mesmo tempo, projecta-se - apresentado como verdade de fora - a auto-imagem humilhante dos "naturais" ${ }^{37}$ como mão-de-obra sem formação à mercê das decisões de governantes que pactuam com os estrangeiros (252) como condição da própria génese nacional. No entanto, a derrota da torre tão bem construída, que conduz até à morte do seu construtor, faz surgir a crítica dos "engenhos estrangeiros que tanto podem estar a favor como contra" (316), parodiando-se assim tanto a 'lenda de auxílio' e a atitude colonizadora como o projecto português de modernização europeia (Grossegesse, 1995, 228).

Reservando uma análise da constelação transcultural entre o cavaleiro alemão Henrique, a sua "barregã" Ouroana ${ }^{38}$ e o soldado Mogueime para outra ocasião, centramo-nos num aspecto de jogo intertextual que ainda recebeu pouca atenção. Face à ausência do episódio da torre móvel e da personalidade de Henrique de Bona na epístola dirigida a Osberno, é significativo que o romance saramaguiano invente "apontamentos para a carta de Osberno" (308) contendo estes, em todo pormenor, a história do cavaleiro Henrique. A explicação psicanalítica de Ersatz para esta escrita do Frei Rogeiro $^{39}$ também é válida para o revisor Raimundo que insere na sua reescrita do Cerco de Lisboa a história da conquista amorosa de Ouroana por Mogueime, possibilitada pela morte do cavaleiro 
alemão, que espelha - através dos tempos - a sua própria 'conquista' de Maria Sara.

Com a ficção do texto apócrifo inaugura-se uma hibridização transcultural das próprias fontes históricas, possibilitando um amalgamar das narrativas dos cruzados com a História nacional e o lendário português que culmina na releitura dos milagres do cavaleiro Henrique, em simultâneo com os milagres de Santo António, o padroeiro mais popular de Lisboa. A intersecção de milagres de ambos, pelas leituras simultâneas de Maria Sara e Raimundo, é um acto que subverte tanto a procura da verdade histórica como o conceito de identidades delimitadas por território, sangue e língua. Numa espécie de metalepse, o próprio Frei Rogeiro, após ter compilado "os apontamentos que havia tomado durante uma volta que dera por todos os arraiais" (331), participa no episódio milagroso "Como o cavaleyro Amrique apareçeo em sonhos a hum homem bõo e como lhe disse que soterasem seu escudeiro a par dele" (Crónica, 51; cf. Indiculum, 84-85), cumprindo o papel daquele homem bom não identificado.

Mais significativo, nesta leitura de milagres transformada em reescrita paródica, é o destaque atribuído à questão de identidades, processos de deslocação e comunicação, culminando na transformação de um milagre do cavaleiro Henrique numa espécie de contra-mito da origem da língua portuguesa: ao narrar o milagre dos dois homens surdos-mudos que se deitaram ao lado do moimento do cavaleiro (Indiculum, 83-84; Crónica, 50-51), realça-se a incerteza da identidade deles: "tinham vindo na frota, porém não se sabe se ingleses, aquitanos, bretões, flandrenses ou colonenses" (335). Estando os dois homens assim jazendo, "adormeceram ambos e apareceu-lhes em sonho logo o cavaleiro Henrique, (...) e falou àqueles mancebos" (336) - não sabemos em que língua anunciando a sua cura, de duvidoso efeito:

(...) e eles acordando acharam que podiam ouvir, e falar também, porém falavam como gagos, e de maneira que não se entendia que língua estavam falando, se a dos ingleses, 
ou aquitanos, ou bretões, ou flandrenses, ou colonenses, ou, conforme não poucos afirmavam, a língua dos portugueses. (336)

Esta manipulação, não de fontes históricas mas de uma lenda, convida para uma leitura metadiscursiva: em vez de "com voz chlara (...) contar a todo o povo o milagre que Deos em eles fizera" (Crónica, 51), os dois ficam gagos. No entanto, o problema não consiste em entender o que é que eles dizem mas em identificar a língua que eles falam. Nesta leitura, o milagre reinterpretado enfatiza a visão de uma hibridização das línguas e das identidades, no entanto consciente da imperfeita capacidade comunicativa, que é aplicável às questões de revisão e tradução.

Tal como o revisor Raimundo Silva dentro da ficção, o tradutor reescreve um texto anterior, no entanto noutra língua e para um leitor com outro horizonte cultural. A procedência das fontes históricas e a apropriação do cavaleiro Henrique pelo discurso da identidade portuguesa demonstram a ineficácia das definições puras de identidade e alteridade. Em vez da tentativa de uma reprodução de uma língua na outra, no fundo irrealizável, a visão da hibridização das línguas e identidades advoga uma recriação, naturalmente sempre parcial e imperfeita, daquela heterogeneidade que História do Cerco de Lisboa exibe ao narrar a procura de uma "verdade" que "não pode ser mais do que uma cara sobreposta às infinitas máscaras variantes, (...)" (26). Para tal, activa-se "outro tipo de relações entre os elementos, (...) porque as coerções impostas pelas línguas levam a diferentes possibilidades de contextualizações, de remissões, de encadeamentos, de atribuição de valores entre os elementos" (Rodrigues, 205). Se o romance reflecte claramente a différance (Derrida, 1967) como princípio universal ${ }^{40}$, destacando os processos de tradução e reescrita, este princípio deve ser válido também para a própria tradução, como propõe Cristina Carneiro Rodrigues, na continuação de Rosemary Arojo (1993): 
O original vive, sobrevive, na e pela sua própria transformação produzida pela leitura. A tradução não transporta uma essência, não troca ou substitui significados dados, prontos em um texto, por significados equivalentes em outra língua. A tradução é uma relação em que o «texto original» se dá por sua própria modificação, em sua transformação. (Rodrigues, 206)

O romance História do Cerco de Lisboa interrelaciona esta condição de cada texto ser texto de textos, transferidos / traduzidos de outros textos, em contextos históricos sempre diferentes, com a crítica da 'origem' da identidade individual e colectiva no sentido de transculturalidade e da "culture's hibridity" (Bhabha, 1989, 38), ambas com base explícita na différance. Se reactivarmos a teoria de Jean Ricardou (1973) relativamente ao nouveau roman, podemos dizer que a aventura da leitura / escrita do revisor prefigura uma aventura semelhante do tradutor. Tal como o revisor transformado em tradutor e autor, ele transmite uma História do Cerco de Lisboa recriada para outro leitor, neste caso um leitor alheio não só à narração tradicional desta história num discurso identitário, mas também à integração da sua identidade cultural neste discurso. Isto torna a tradução deste romance uma aventura de leitura e reescrita, em certa medida já prevista na História do Cerco de Lisboa:

Se, no processo de tradução, o tradutor, ou tradutora, tem que necessariamente tomar o lugar do autor e se apossar de seu texto para que esse possa sobreviver em outra língua, não há como eliminar esse momento de usurpação e conquista, que a reflexão desconstrutivista flagra e desmascara. (Arrojo, 1993, 82)

Curiosamente, Rosemary Arrojo emprega a mesma metáfora de conquista utilizada para a aventura de Raimundo Silva que abrange a conquista amorosa de Maria Sara. ${ }^{41}$ É precisamente a mulher 
que apoia a conquista de um texto que não lhe pertence e motiva a sua sobrevivência ou até mesmo o seu auto-nascimento, em conformidade com a poética saramaguiana..$^{42} \mathrm{O}$ romance acaba numa subtil reivindicação do pneuma, anterior ao $\log o s$, personificado no almuadem que permanece, depois de degolado, "uma sombra" que respira sob "o alpendre da varanda", precisamente no lugar fronteiriço da Cerca Moura onde descansam Maria Sara e Raimundo Silva (P 348). A reivindicação deste entre-lugar também é válida para qualquer tradução da História do Cerco de Lisboa.

\section{Notas}

1. O advérbio 'recentemente' refere-se ao contexto inicial deste estudo, quando apresentado no Colóquio Internacional sobre Estudos de Tradução, (orgs.) Marian Schoenmakers \& Vera Fonseca, Univ. Utrecht (Holanda), Junho de 2006. Não chegando a haver Actas deste evento, agradeço à Prof. ${ }^{a}$ Andréia Guerini a oportunidade desta publicação posterior.

2. no fundo já interiorizada como "contra-imagem auto-humilhante" (Lourenço, 75).

3. O leitor não confunda os dois senhores Welsh e Welsch. Parece-me uma coincidência curiosa de precisamente o adjectivo homófono "welsch" (vindo do alemão antigo walasg e walahisc) denominar o outro, o estrangeiro (= o indivíduo vindo do Sul da Europa: latino, romano), oposto ao próprio (= "deutsch", vindo de diutisc $=$ pertencente ao povo).

4. "im Bewußtsein seines gegenwärtigen Standorts in der historischen Reihe der Leser" (Jauss, 171). Todas as traduções de bibliografia passiva são do autor deste estudo.

5. O texto português e o texto da tradução alemã (tradutor Andreas Klotsch) citados com as siglas $\mathrm{P}$ e $\mathrm{T}$, respectivamente. 
6. "Cultures are never unitary in themselves, nor simply dualistic in the relation of Self to Other." (Bhabha, 1989, 35-36).

7. Para facilitar a leitura deste estudo, falamos sempre do 'livro do historiador' para identificar o texto historiográfico cuja revisão leva Raimundo Silva, paulatinamente, a actos de reescrita que, por sua vez, são objeto da ficção do romance História do Cerco de Lisboa.

8. "Enquanto não alcançares a verdade, não poderás corrigi-la. Porém, se a não corrigires, não o alcançarás. Entretanto não te resignes."

9. Antigamente atribuída por alguns investigadores a Fernão Lopes, é publicada pela primeira vez em 1945 e recebe posteriormente a designação Crónica de Portugal de 1419 (ed. crítica de Adelino de Almeida Calado, 1998). Para além dos mencionados, o romance saramaguiano cita ainda o Indiculum fundationis Monasterii beati Vincentii ulixbone (em latim, séc. XIII; versão portuguesa entre 1340 e 1400).

10. Esta visão global europeia, já presente na História de Portugal, Livro II, de Alexandre Herculano (486-87), reaparece num texto jornalístico, motivado pelo "choque violento entre duas culturas" no Médio Oriente por ocasião da Guerra do Iraque. De passagem, oferece-se uma versão da conquista de Lisboa que mostra, para além da habitual superficialidade histórica, uma surpreendente indiferença relativamente à narrativa fundacional portuguesa: "Organizaram-se ainda diversas cruzadas de menores dimensões. Uma delas, compostas por soldados ingleses e dinamarqueses, conquistou Lisboa aos mouros (por iniciativa do bispo do Porto) em 1147 e entregou-a a D. Afonso Henriques - que, como sabemos, também participou no cerco.” (Martins, 138)

11. Cf. a análise dos "Jogos Intertextuais" no contexto teórico de Bakhtin e Hutcheon in Caragea (2003, 232-241). Ao destacar a capacidade do revisor para "polifónicos edifícios verbais" (22), o romance saramaguiano revela claramente a consciência deste contexto.

12. "Labrego - Indivíduo cretino; grosseiro; provinciano." (Nobre, 93)

13. Istoria asediului Lisabonei, Bucareste: Ed. Univers, 1998; prefácio sob o título "Jocul cu Istoria" [Jogo com a História], pp. 5-16. Um estudo comparativo desta tradução está em preparação. 
14. "Jede Übersetzung steht für einen Ausgangstext und statt eines Ausgangstextes in der Zielliteratur. Ihre Kommentierung oder Nichtkommentierung entscheidet sich danach, welcher Aspekt der Janusköpfigkeit akzentuiert wird. Übersetzungen sind aber auch in jeder Literatur ein privilegierter Ort zur Artikulation von Differenzqualitäten.” (Turk, 3-4)

15. Trata-se de um documento encontrado na Biblioteca do Colégio do Corpo de Cristo, da Universidade de Cambridge, copiado pelo paleógrafo N. E. Hamilton e publicado pela primeira vez em 1856, numa versão anotada, por Alexandre Herculano nos Portugaliae Monumenta Histórica, Scriptores, vol. I.. Baseia-se nela nomeadamente o famoso olisiponense Júlio de Castilho em Lisboa Antiga (vol. II), realizando "a mais pormenorizada narração do cerco e da conquista de Lisboa", nas palavras de outro olisiponense, Augusto Vieira da Silva (Conquista, 9), no prefácio da edição bilingue (latim / português) da carta, provavelmente consultada por Saramago na génese do seu romance.

16. $V d$. a definição no pacto dos sitiadores ("pactum inter me et francos, quod scilet ego Hydefonxus rex portugalensium"; Conquista, p. 50) e o louvor da conquista: "magnificatum est francorum nomen per universas Hyspaniae partes, irruitque timor super mauros quibus verbum hujus actionis divulgabatur." (Conquista, 84).

17. "Em rigor, Portugal não nasceu do Condado Portucalense, a não ser no que respeitou à dinastia reinante e à elite nobre que a circundava. Quase todas as estruturas vigentes no Sul islâmico - propriedade, economia, boa parte dos estrados médios e inferiores da sociedade, grande parte do municipalismo e da organização do Estado, religião, língua e até cultura - exerceram papel relevante na constituição do novo país.” (Marques, 69)

18. “(...), es bestehen große Zweifel, ob der Erzbischof von Braga unseres lusitanischen Blutes ist, nun ja, schon in jenen alten Zeiten war die von uns bis heute aufrechterhaltene Fama im Schwang, daß wir Leute von außen freundlich aufnehmen und sie mit Posten und Pfründen versehen, (...). “ (240; negrito nosso)

19. (Alves, 12). Não conseguimos averiguar se a data da primeira edição de Alves $(2004)^{2}$ é anterior à publicação de História do Cerco de Lisboa (1989). Importa referir que esta discussão já é antiga (David, 1936, pp. 43-45). Por isso, Saramago pode ter lido comentários de vária origem. Um ano após a publicação, a questão é novamente discutida por Livermore (1990) que chega a identificar, de forma convincente, o autor como Raol, um padre de identidade mista anglofrancês, do círculo próximo de Hervey de Glanvill / Glanville, que participa nos 
acontecimentos que narra. A identidade do destinatário é Osberto of Bawdsey, um clérigo pertencente à poderosa família Glanville, em East Anglia.

20. "Indicto ab omnibus silentio, episcopus sermonem coram omnibus lingua latina habuit, ut per interpretes cujusque linguae sermo ejus omnibus manifestaretur, qui sic incipit: (...)." (Conquista, 27)

21. "Sed ne populorum conclamationibus vestrorum nostra turbetur oratio, ex vobis eligite (...)." / "Ora, para que, com a algazarra dos vossos homens não seja perturbado o que vos disser, escolhei quem vós quiserdes, (...)” (Conquista, 45); reproduzido tal qual no romance (45).

22. Ao traduzir "nacionalidade" por "Abkunft" (origem). Na primeira ocorrência de "algazarra", no discurso régio, a versão alemã conserva igualmente a palavra, seguida pela sua tradução, assinalando assim a diferença: "Nun, damit die algazarra, der wilde Lärm eurer Männer, nicht übertöne und verwirre, was zu sagen ihr gedenkt, erwählt nach Belieben eure Sprecher (...).” (53)

23. "Imfra quam cartae plurimis transmissae lingua caldea inscriptae repertae sunt. Exemplum unius sicut per interpretem didici hujusmodi erat: «Abbati Machumato Eburensium regi calamitas Lixbonensium, (...).»”(Conquista, 63-64)

24. Uma consciência já assinalada desde o início, por exemplo no comentário crítico: “(...) mas balas não é palavra daquele tempo, as palavras não podem ser levianamente transportadas de cá para lá e de lá para cá, cuidado, aparece logo alguém que diz, Não percebo.” (33)

25. "Episcopum vero civitatis antiquissimum praeciso jugulo contra jus et fas occidunt." (Conquista, 83). A re-imaginação da matança de todos os cristãos moçárabes (começando pela degolação do bispo) como resultado de uma 'operação de limpeza' conforme a ideologia da pureza cristã (Bernardo de Claraval) que dominou a segunda cruzada (1147/48) é tema do recente romance 1147. O Tesouro de Lisboa (2006), de Paulo Moura. A bibliografia não inclui o romance de Saramago.

26. Vd. comparação (Grossegesse, 1994). No breve texto dedicado a Juan Goytisolo, Saramago (1994) não faz nenhuma referência a esta obra, nem a Juan sin Tierra (1975), falando só de "uma obra ampla e poderosa, caracterizada por sucessivas rupturas, tanto temáticas como estilísticas, e eticamente marcada por uma implacável revisão axiológica." 
27. (63). Na ocorrência anterior (40) a tradução alemã marca com "Namensvetter des anderen" (T 46) claramente este desdobramento.

28. (175; 247). No primeiro caso, a tradução alemã ainda fala de "Franken und Gallier" (T 211) em vez de "Galicier" (300). Numa dimensão histórica, a identidade de "Franken" é polivalente.

29. No entanto, não chega a ocorrer uma "troca de fios" no tecido da musa Clio, como no conto A Inaudita Guerra na Avenida Gago Coutinho (1992) de Mário de Carvalho: concretamente, entre a tentativa de uma reconquista árabe de Lisboa, em 1148, e a vida lisboeta de 1984, com lembranças pós-revolucionárias.

30. O vocabulário de José Pedro Machado (69) refere a existência das variantes "almoedam" e almoádam" na Crónica da Tomada de Ceuta e no Livro do Falcoaria de Pêro Menino, do século XV, adaptações da palavra árabe "al-muadh-dhan” (o pregoeiro que do alto da torre da mesquita chama à oração).

31. No caso de “almádena” não há alternativa à tradução por “Minarett” $(348 ; 425)$.

32. Citado conforme a edição bilingue de 1935, com tradução de José Augusto de Oliveira: "Em cerca de cento e sessenta e quatro navios reuniram-se no Porto de Dartmouth, homens de diversas nacionalidades, costumes e línguas. O exército formado por todos eles acha-se dividido em três partes: sob o comando do conde de Arnoldo de Aarschot, neto do duque de Godofredo, estão os homens vindos das regiões do império romano; Cristiano de Gistell comanda os de Flandres e Bona; (...)." (Conquista, 22).

33. "Entenda-se o antigo império germânico" (Conquista, 22; nota 1). Nota eliminada em Alves (2004).

34. Aparecem também "bolonenses" (Conquista, 46). No entanto, seria errado identificá-los como vindo de Bolonha em Itália, como sugere o texto saramaguiano e, consequentemente, a tradução alemã. Este grupo de cruzados, "que acampava juntamente com os flandrenses e colonenses na parte oriental da cidade" foram “originários de Boulogne-sur-mer" (13), uma cidade portuária importante que os romanos chamaram Bolonia. Ela pertence à diocese de Thérouenne (Taruanna), onde o bispo Milão (Milo) acolheu os alemães que haviam saído de Colónia e 
abençoou as naus da expedição, antes de eles se encontraram com os outros em Dartmouth (Alves, 73).

35. Neste texto referem-se repetidas vezes "colonenses", sempre unidos aos "flandrenses" (Conquista, 46/62). Supondo um conhecimento geográfico da proximidade entre Colonia e Bona, a versão "bononenses" em vez de "bolonenses" fica reforçada.

36. Herculano (508), com base na carta do cruzado Arnulfo ao bispo Milão (Epistola Arnulfi ad Milonem Episcopum Morinensem). Tanto Herculano (nota 138) como posteriormente Alves (nota 41) destacam a divergência entre a carta de Arnulfo e a carta a Osberno. Paulo Moura $(2006,95)$ refere a procedência do novo engenho de Pisa, comentado como "ridiculamente moderno" e "a moda de Constantinopla”.

37. A tradução "hiesige Eingeborene" revela claramente o olhar colonizador do cavaleiro alemão.

38. "barregã de um cruzado alemão" (254). O narrador analisa a dependência histórica e cultural desta palavra ao negar a sua aplicação a Maria Sara, "que não é barregã de ninguém": "as diferenças, que as há, são culturais, sim senhor." (255). Tradução alemã que intenta reproduzir a historicidade: "Bettschatz" (310).

39. “(...), diremos que não podendo Frei Rogeiro satisfazer em Ouroana os apetites, não encontrou melhor exutório, salvo outro qualquer secreto, que exaltar até à desmedida o homem que se gozava do corpo dela.” (309)

40. Basta citar a imagem central do romance: “(...), os livros estão aqui, como uma galáxia pulsante, e as palavras, dentro deles, são outra poeira cósmica flutuando, à espera do olhar que as irá fixar num sentido ou nelas procurará o sentido novo, porque assim vão variando as explicações do universo, também a sentença que antes parecera imutável para todo o sempre oferece subitamente outra interpretação, a possibilidade de uma contradição latente, a evidência do seu erro próprio." (26)

41. Perante esta analogia surpreende que a interpretação do próprio romance saramaguiano por parte de Rosemary Arrojo fique limitada à "idealização romântica" do poder autoral (Arrojo, 2003, 203), negligenciando toda a riqueza de dialogismo e sucessiva reflexão meta-discursiva. 
42. A análise do acto de traduzir como tema literário também se aplica ao caso do revisor Raimundo Silva: traduzir "significa uma renúncia dupla da subjectividade viva: renunciar à plenitude do jogo dos significados e à constituição do sentido próprio. (...) Na literatura, o traduzir é representado como actividade de pessoas já trans-feridas, longe do seu próprio Eu ou longe da vida activa." (Klein, 119-120). No caso do revisor, a introdução do "Não" inicia o abandono de conformidade passiva, sendo a visibilidade textual do revisor o germe de um 'auto-nascimento' (Grossegesse, 1999, 68-77).

\section{Referências}

Alves, José Felicidade (2004), Conquista de Lisboa aos Mouros em 1147. Carta de um cruzado Inglês que participou nos acontecimentos, Lisboa: Livros Horizonte ( $2^{\mathrm{a}}$ ed.).

Arrojo, Rosemary (1993), Tradução, desconstrução, psicanálise, Rio de Janeiro: Imago.

. (2003), “A relação exemplar entre autor e revisor (e outros trabalhadores textuais semelhantes) e o mito de Babel: alguns comentários sobre História do Cerco de Lisboa, de José Saramago”, D.E.L.T.A., 19: Especial, pp. 193-207.

Bassnett, Susan (1998), “The Cultural Turn in Translation Studies", in: Laurence Raw, Gülriz Büken, Günseli Sönmez Ýpçi (eds.) The History of Culture: The Culture of History, Ankara: The British Council.

Bhabha, Homi (1985), "Signs Taken for Wonders: Questions of Ambivalence and Authority under the Tree outside Delhi, May 1817”. In: id. (1994), The Location of Culture, London/New York, pp. 102-122.

. (1989), "The Commitment to Theory". In: id. (1994), The Location of Culture, London/New York, pp. 19-39. 
. (1994), "DissemiNation: Time, Narrative and the Margins of the Modern

Nation". In: id., The Location of Culture, London/New York, pp. 139-170.

Brockhaus Lexikon (1989). Edição Deutscher Taschenbuch Verlag, 20 vols.

Conquista de Lisboa aos Mouros (1147) narrada pelo Cruzado Osberno, testemunha presencial. Texto latino Crucesignati anglici epistola de expugnatione olisiponis e sua tradução para português pelo Dr. José Augusto de Oliveira. Prefácio do Engenheiro Augusto Vieira da Silva. Lisboa: Câmara Municipal de Lisboa 1935.

Caragea, Mioara (2003), A leitura da história nos romances de José Saramago, Bucareste: Ed. Univ. Bucareste.

Crónica de Portugal de 1419. Edição crítica de Adelino de Almeida Calado, Aveiro : Univ. de Aveiro 1998.

David, Charles Wendell (1936), "Introduction", in: The Conquest of Lisbon. De Expugnatione Lyxbonensi. Trad. C.W. David, New York: Columbia Univ. Press; reed. 2001 (prefácio / bibliografia Jonathan Phillips).

Derrida, Jacques (1967), L'écriture et la différance, Paris: Seuil.

Ehrhardt, Marion (1980), “As primeiras notícias alemãs acerca da cultura portuguesa / Erste Nachrichten über die portugiesische Kultur”, in: id., Rainer Hess e Jürgen Schmidt-Radefeldt (orgs.), Portugal - Alemanha / Portugal Deutschland, Coimbra: Almedina, 11-65 [bilingue, com ilustrações e bibliografia].

Goytisolo, Juan (1970), Reivindicación del conde don Julián, México: Joaquín Mortiz. Ed. cit. Biblioteca Breve, Barcelona: Seix Barral 1976. . (1975), Juan sin Tierra, Biblioteca Breve, Barcelona: Seix Barral.

Grossegesse, Orlando (1994), “Die Rückforderung von Al Usbuna”, Tranvía 33, Berlin, pp. 7-9. 
. (1995), "Das Deutsche und das Europäische im Werk José Saramagos", in: Portugal und Deutschland auf dem Weg nach Europa, (orgs.) Marília dos Santos Lopes, Ulrich Knefelkamp, Peter Hanenberg. Pfaffenweiler: Centaurus, 1995, pp. 221-231.

. (1996), "La actualiad del 'desnarrar'. José Saramago ante la Historia", in: Mundos de Ficción. Investigaciones Semióticas VI (Actas del VI Congreso AES 1994), (orgs.) J.M. Pozuelos Yvancos / Francisco Vicente Gómez. Univ. Murcia, vol.II, pp. 805-812. . (1999), Saramago lesen, Berlin: edition tranvía.

Herculano, Alexandre (1980), História de Portugal, ed. cit. Lisboa: Bertrand (Tomo I).

House, Juliane (2002), "Universality versus culture specificity in translation". In: Translation Studies. Perspectives on an Emerging Discipline. (org.) Alessandra Riccardi. New York: Cambridge Univ. Press, pp. 92-109.

Indiculum fundationis Monasterii beati Vincentii ulixbone. Versão portuguesa: Crónica da Tomada de Lisboa. Edição fac-similada, paleográfica e crítica de Fernando Venâncio Peixoto da Fonseca, Lisboa 1995.

Iser, Wolfgang (1972), Der implizite Leser, München: Fink.

Jauss, Hans Robert (1970), Literaturgeschichte als Provokation, Frankfurt / Main: Suhrkamp.

Kaufman, Helena (1991), “A metaficção historiográfica de José Saramago”, Coloquio / Letras 120, 124-136.

Klein, Judith (1996), "Sinnzerstörung und Tod. Übersetzen als Thema und Metapher der modernen Literatur”. In: Literarische Polyphonie, (org.) Peter V. Zima, Tübingen: Gunter Narr, 113-122.

Lefevere, André (1992), Translation, Rewriting and the Manipulation of Literary Frame, Routledge: London / New York. 
Livermore, Harold (1990), "The Conquest of Lisbon and Its Author", Portuguese Studies 6 (1990), pp. 1-16.

Lourenço, Eduardo (1978), "Repensar Portugal". In: O Labirinto da Saudade, ed. cit. Lisboa: Publicações Dom Quixote, ${ }^{4} 1991$, pp.65-78.

Machado, José Pedro (1991), Vocabulário Português de Origem Árabe, Lisboa: Ed. Notícias.

Marques, A.H. Oliveira (1995), Breve História de Portugal, Lisboa: Presença.

Martins, Luís Almeida (1991), "Cruzadas: Epopeia ou ignomínia?”, Visão, $\mathrm{n}^{\circ}$ 451, 25 de Outubro de 2001, pp. 136-139.

Moura, Paulo (2006), 1147. O Tesouro de Lisboa, Lisboa: A Esfera dos Livros.

Nobre, Eduardo (1986), Dicionário de Calão, Lisboa: Dom Quixote.

Oliveira, José Augusto de (1935), "Advertência”. In: Conquista de Lisboa aos Mouros, Lisboa: Câmara Municipal de Lisboa, pp. 15-19.

. (1940), "D. Afonso Henriques empreendeu a conquista de Lisboa sem contar com o auxílio dos cruzados". In: Congresso do Mundo Português, $2^{\circ}$ vol., Lisboa: Comissão Executiva dos Centenários.

Pereira, José Pacheco (2006), “Mal-amados”, Público, 1 de Junho de 2006, p. 5.

Prince, Gerald (1988), “The Disnarrated", Style 22/1, pp. 1-8.

Ricardou, Jean (1973), Le Nouveau Roman, Paris: Seuil.

Rodrigues, Cristina Carneiro (1999), Tradução e diferença, São Paulo: UNESP.

Saramago, José (1989), História do Cerco de Lisboa, Lisboa: Caminho. = P 
. (1992) Geschichte der Belagerung von Lissabon, Reinbek bei Hamburg: Rowohlt. Trad. Andreas Klotsch. = T . (1994), „Juan Goytisolo“, Espacio / espaço escrito, vol. 9 / 10, Badajoz, pp. 7-8.

. (1996), The History of the Siege of Lisbon, London: The Harvill Press. Trad. Giovanni Pontiero.

Stoll, Karl-Heinz (2005), "Translation als Kreolisierung”, http://www.fb06.unimainz.de/inst/iaa/vorl/transkreo.pdf

Turk, Horst (1992), “Übersetzung ohne Kommentar. Kulturelle Schlüsselbegriffe und kontroverser Kulturbegriff am Beispiel von Goytisolos Reivindicación del Conde don Julián", in: Die literarische Übersetzung als Medium der Fremderfahrung, (ed.) Fred Lönker, Berlin, pp. 3-40.

Welsch, Wolfgang (1995), “Transkulturalität. Zur veränderten Verfaßtheit heutiger Kulturen”, Zeitschrift für Kulturaustausch, 45/1, pp. 39-44.

Recebido em: 01/09/2014

Aceito em: 07/11/2014 